\title{
CORRIGENDA
}

\section{Reelin, an extracellular matrix protein linked to early onset psychiatric diseases, drives postnatal development of the prefrontal cortex via GluN2B-NMDARs and the mTOR pathway}

J lafrati, MJ Orejarena, O Lassalle, L Bouamrane and P Chavis

Molecular Psychiatry (2014) 19, 527; doi:10.1038/mp.2013.148; published online 22 October 2013

Correction to: Molecular Psychiatry advance online publication, 11 June 2013; doi:10.1038/mp.2013.66

Following the publication of this paper, the authors decided to include C Gonzalez-Campo as an author. Her earlier work facilitated the research presented in the paper. The revised author list appears below:
J lafrati, MJ Orejarena, O Lassalle, L Bouamrane, C Gonzalez-Campo and $\mathrm{P}$ Chavis

Dr Gonzalez-Campo is associated with the following affiliation: INSERM U862, Neurocentre Magendie, Pathophysiology of Synaptic Plasticity Laboratory, Bordeaux, France.

\section{Allelic differences between Europeans and Chinese for CREBI SNPs and their implications in gene expression regulation, hippocampal structure and function, and bipolar disorder susceptibility}

M Li, X-j Luo, M Rietschel, CM Lewis, M Mattheisen, B Müller-Myhsok, S Jamain, M Leboyer, M Landén, PM Thompson, S Cichon, MM Nöthen, TG Schulze, PF Sullivan, SE Bergen, G Donohoe, DW Morris, A Hargreaves, M Gill, A Corvin, C Hultman, AW Toga, L Shi, Q Lin, H Shi, L Gan, A Meyer-Lindenberg, D Czamara, C Henry, B Etain, JC Bis, MA Ikram, M Fornage, S Debette, LJ Launer, S Seshadri, S Erk, H Walter, A Heinz, F Bellivier, JL Stein, SE Medland, AA Vasquez, DP Hibar, B Franke, NG Martin and MJ Wright, MooDS Bipolar Consortium, The Swedish Bipolar Study Group, The Alzheimer's Disease Neuroimaging Initiative, ENIGMA Consortium,

CHARGE Consortium and B Su

Molecular Psychiatry (2014) 19, 527; doi:10.1038/mp.2013.73; published online 14 May 2013

Correction to: Molecular Psychiatry advance online publication, 9 April 2013; doi:10.1038/mp.2013.37

After the above article was published, the authors noted that $L$ Gan was linked to the wrong affiliation. Additionally, $\sqcup$ Launer's affiliation was listed incorrectly. The correct affiliations appear below.

$\mathrm{L} \mathrm{Gan}^{3}$

${ }^{3}$ University of Rochester Flaum Eye Institute, University of Rochester, Rochester, NY, USA

LJ Launer ${ }^{32}$

${ }^{32}$ Intramural Research Program, National Institute on Aging, National Institutes of Health, Bethesda, MD, USA
Also, on page 4 of the Supplementary Information, the heading 'Replication Sample Information: See Supplementary Table S2' should read 'Replication Sample Information: See Supplementary Table S1'.

In the Supplementary Information, affiliation 1 was not listed in its entirety. The complete affiliation is Department of Genetic Epidemiology in Psychiatry, Central Institute of Mental Health, Medical Faculty Mannheim, University of Heidelberg, D-68159 Mannheim, Germany. 